\title{
Evaluation of Energy Storage System to Support Danish Island of Bornholm Power Grid
}

Cha, Seung-Tae; Zhao, Haoran; Wu, Qiuwei; Østergaard, Jacob; Nielsen, Torben Skov; Madsen, Henrik

Published in:

Proceedings of 10th International Power and Energy Conference

Publication date:

2012

Link back to DTU Orbit

Citation (APA):

Cha, S-T., Zhao, H., Wu, Q., Østergaard, J., Nielsen, T. S., \& Madsen, H. (2012). Evaluation of Energy Storage System to Support Danish Island of Bornholm Power Grid. In Proceedings of 10th International Power and Energy Conference IEEE.

\section{General rights}

Copyright and moral rights for the publications made accessible in the public portal are retained by the authors and/or other copyright owners and it is a condition of accessing publications that users recognise and abide by the legal requirements associated with these rights.

- Users may download and print one copy of any publication from the public portal for the purpose of private study or research.

- You may not further distribute the material or use it for any profit-making activity or commercial gain

- You may freely distribute the URL identifying the publication in the public portal 


\title{
Evaluation of Energy Storage System to Support Danish Island of Bornholm Power Grid
}

\author{
Seung Tae Cha, Haoran Zhao, Qiuwei Wu, Jacob Østergaard, Torben S. Nielsen, Henrik Madsen \\ Technical University of Denmark \\ Center for Electric Technology \\ 2800 Lyngby, Denmark \\ \{stc, hzhao,qw,joe\}@elektro.dtu.dk $\{t s n, h m\} @ e n f o r . d k$
}

\begin{abstract}
This paper presents a real-time evaluation and simulation approach of energy storage system (ESS) based on large renewable-based electricity generation, which can be used for grid support. The ESS is designed to maintain power quality as a primary regulation, while the conventional generation units handle the secondary frequency regulation to mitigate ramping issues. The real time models of Bornholm distribution grid, which is the combination of an aggregated wind power generation and the energy storage system (ESS) has been used to test the system and control approach in a real time grid simulator to identify the improvement of the grid support capability. The interactive simulation platform with real-time energy forecasting data running online with a link to the Bornholm power system data are being used to measure and validate the system performance with and without energy storage after a disturbance.
\end{abstract}

Keywords-component; Energy storage system (ESS), Grid support capability, Primary/secondary regulation, Ramping issues, Real time digital simulator (RTDS), Renewable-based electricity generation, Wind forecasting system

\section{INTRODUCTION}

Denmark is a unique place for renewable energy utilization and smart grid technology development. One of the strong drivers for this is owing to its very pro-active energy policy. More renewable energy integration is planned in near future. In 2011, the wind power generation covered $28 \%$ of the demand (incl. grid losses). The Danish parliament has entered a new energy agreement and set a target of $50 \%$ penetration of wind power in 2020 and $100 \%$ penetration of renewable energy in 2035 [1]. In regards to the future energy system, Bornholm is in the center of attention in most of Europe and some parts of the world due to the characteristics of the Bornholm power system. Bornholm has set some of the most aggressive state renewable energy targets in the country $-50 \%$ renewables by 2030. Energy partners from the Transmission System Operator (TSO), Energinet.DK, Distribution System Operator (DSO), Østkraft and Technical University of Denmark (DTU) will collaborate on several on-going smart grid demonstration projects on Bornholm aimed at improving integration of renewable energy resources to the electric system in preparation for a smart grid future. In general, the islands are proving to be excellent test beds for the introduction of new technologies. Hence, Bornholm is the ideal place to demonstrate new energy concepts and becomes a new energy lab with great international focus. Furthermore, a peak load of around $60 \mathrm{MW}$ on the island, up to $30 \mathrm{MW}$ can come from wind energy. Presently, Bornholm receives nearly $33 \%$ of its energy from wind, with plans to add even more wind-powered generation. That is an additional wind power of 20MW estimated to be installed and $5 \mathrm{MW} \mathrm{PV}$ roll-out (i.e corresponds to penetration level of $10 \%$ close to the European Photovoltaic Industry Association's goal for 2020) in the coming years. With this emerging renewable and distributed generation future scenario, there is a great possibility that these variable generation resources may increase grid volatility, requiring increased grid support/ancillary services to help maintain stable, reliable, and robust grid operations. This problem can become even more acute for island applications with the conventional system balancing methodologies. The challenge is integrating a high-penetration of alternative energy, without sacrificing electric grid reliability, availability, and power quality. Increasingly intermittent renewable generation threatens the already delicate balance of supply and demand on today's Bornholm power grid. New features addressing the intermittent nature of these variable generation resources should be added into power system control and planning, so that systems with smart grids can be operated safely. In order to handle the challenges and problems, a rethink of the existing energy balancing paradigm must be required. This can be achieved in many ways from an increasing the cross-border transmission lines, demand side response/management, increased flexibility of conventional power plants, and energy storages [2][3]. The energy storage system (ESS) is among the most efficient and compatible technologies for an improved power system operation and control with large renewable-based electricity generation. Storage technologies can certainly play these key roles and help restore the grid's balance. The ESS can charge whenever there is an excess of electricity in the connected system and discharge when required by the grid. This particular solution is one of the emerging concepts and is the focus of this work as energy storages may become cost effective in future.

The various sections in this paper are organized as follows. Section II discusses the overview of PowerLabDK, simulation platform. Modelling of the Bornholm power 
system is discussed in Section III. The simulation results are presented in Section IV and concluded in Section V.

\section{SimUlation PlatForm}

A world class experimental platform named PowerLabDK, has been established. The PowerLabDK is a unique global experimental platform. This platform can be used for different types of research ranging from basic research to large-scale and full-scale experiments. It is comprised of the High Power Lab in the Copenhagen University College of Engineering (IHK), the Intelligent Control Lab (ICL), Electric Lab, High Voltage Lab and Power Student Lab in DTU Lyngby campus, a large scale test system (SysLab) and the PowerFlexHouse facility in DTU Risø campus and a full scale power system in the island of Bornholm (28,000 customers and $33 \%$ wind power penetration). In particular, the ICL is a simulation platform comprising a real time digital simulator (RTDS), a full scale ABB Network Manager SCADA system, a full-scale experimental power system control room, an IBM blade centre for optimization and control implementation, a PMU lab, a $150 \mathrm{~kW}$ power amplifier, and 21 LabCell boards [4]. The system setup of the ICL is shown in Fig. 1.

\section{A. Real Time Intelligent Control Laboratory}

The ICL has 5 racks of RTDS. The RTDS racks are equipped with 4 GPC cards for each and the RTDS system can simulate a power system with up to 110 buses. The RTDS system has been recently upgraded with the latest generation of the PB 5 processor cards, and significantly increased the size of the simulated network.

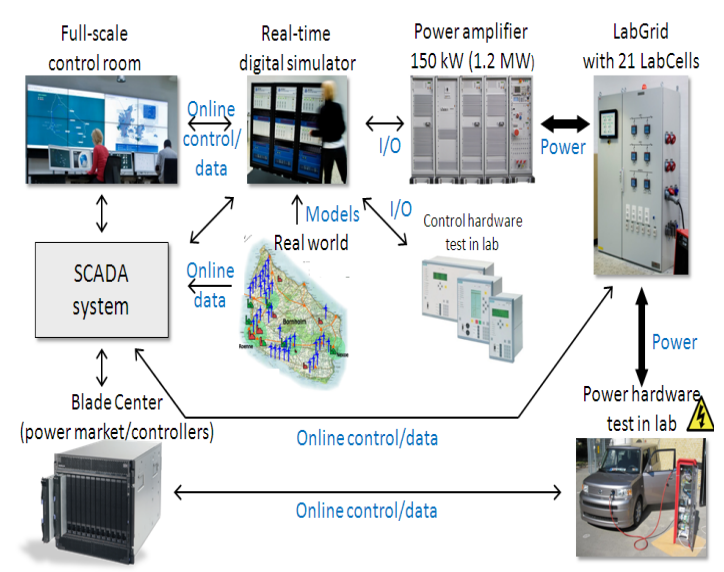

Figure 1. ICL system setup

\section{B. Bornholm Energy Forecasting System}

While renewable energy can not necessarily be operated in a conventional manner, its behavior can be predicted and the forecast information is exactly the kind of information that an island power grid must use to improve system efficiency. In fact, as renewable energy penetration levels continue to increase, non-scheduled renewable energy may become the single largest source of variability on the power system. This makes the employment of accurate renewable energy forecasting a key component. As another valuable asset, the PowerLabDK also offers the complete forecasting system under development by the Danish forecasting experts from ENFOR A/S, which consists of wind power prediction tool (WPPT), heat load prediction and energy systems optimization (PRESS), electricity load prediction (LOADFOR), power price prediction (PRICEFOR), and solar power prediction (SOLARFOR) covering Bornholm island for research purposes. This particular forecasting system has been used together with the RTDS for validation of Bornholm power grid. The detailed information on the forecast system is available in [5] and hence is not repeated. A brief description of the WPPT is provided. The WPPT can be used for generating short-term (i.e $1 \mathrm{hr}$ to $168 \mathrm{hrs}$ ) predictions of the wind power production. The system is very flexible and it can be configured to cover the total wind power (i.e entire Bornholm), the total wind power in a region (i.e Eastern part of Bornholm), or a single wind farm (i.e WRW). The main window in WPPT running in online mode and the preferred future setup of forecasting system are depicted in Fig. 2, and Fig. 3, respectively.

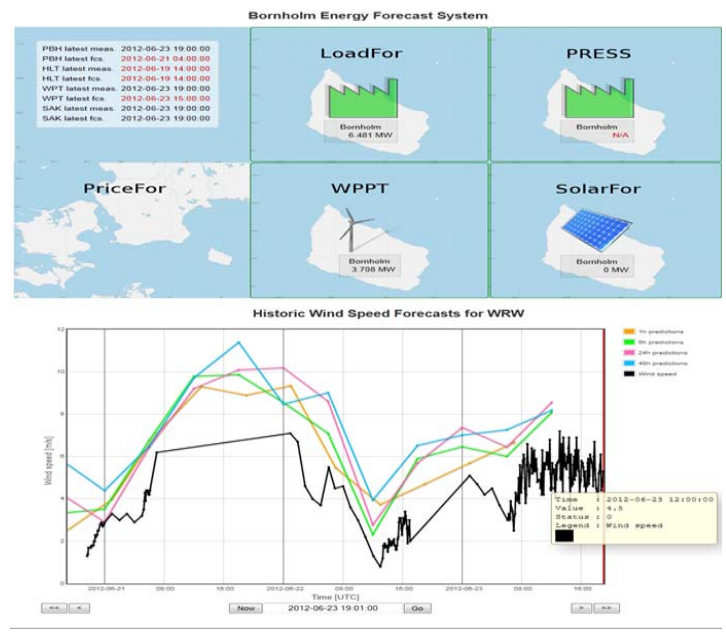

Figure 2. Main window in WPPT and wind speed for Bornholm island

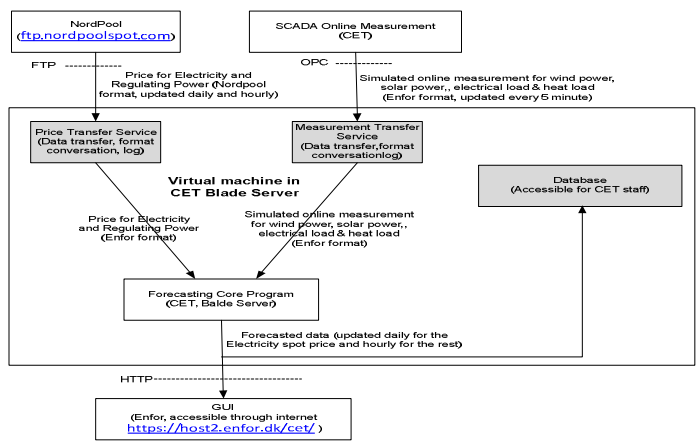

Figure 3. Preferred future setup of forecasting system 


\section{TEST SYSTEM}

\section{A. Bornholm Power System}

The Danish power system is electrically separated into two parts, the western part connected to the Union for the Coordination of Electricity Transmission (UCTE) system and the eastern part connected to the Nordic synchronous area. The island of Bornholm is part of the Nordic power system where the secondary control operation is manually operated. The Bornholm power system is connected through a long submarine cable to the Swedish power system, represented in the model as a simple external grid. The power system contains both $60 \mathrm{kV}$ and $10 \mathrm{kV}$ buses. A detailed description and the parameters can be found in [6]. The basic Bornholm model has been slightly modified and the final test system used in this simulation is depicted in Fig. 4. The Bornholm system also consists of an aggregated WPPs modeled jointly as a 2 MW generation unit plus energy storage system (ESS) from [7]. The WPP and ESS are connected to the grid at the point of common coupling to be utilized in order to provide backup power to ensure that the main frequency of the Bornholm grid remains under constant control at the steady $50 \mathrm{~Hz}$ required for grid stability. The complete forecasting system with a link to the Bornholm power system data provides real-time varying wind speed incorporated into the RTDS has been used to conduct more realistic simulation.

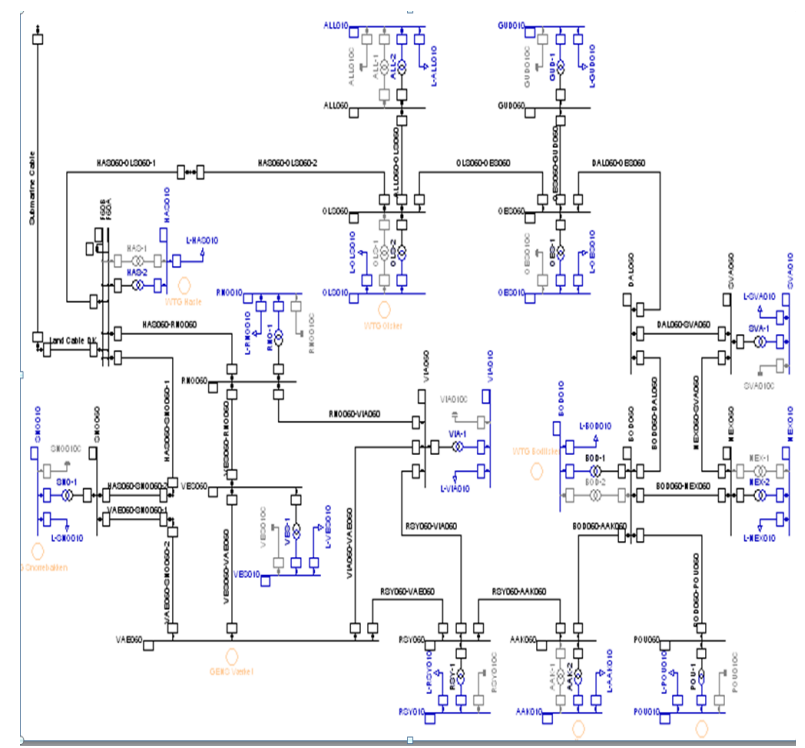

Figure 4. Single line diaram of detailed power system of Bornholm

\section{B. Energy Storage System}

The ESS enables smoothing of fluctuations for wind and solar generation units. The system provides a mechanism to store intermittent energy generation, which provides consistent power to the grid. Quick-response characteristic alleviates rapid shifts in renewable energy generation and can therefore act as a frequency regulator. In practice, the
ESS consists of rectifier/inverter, battery cells and the Energy Management System (EMS). The rectifier/inverter is normally based on a voltage source converter (VSC) and a pulse width modulation (PWM). It acts as the interface between DC and AC sides. If the converter losses, internal dynamics of battery cells and battery capacity are ignored, the battery can be regarded as the controlled current sources for three phases. This simplified model is depicted in Fig. 5, and implemented in this study. The EMS manages the active and reactive power exchange. There are different control objectives for EMS. Here, the tasks are stabilizing the grid frequency and voltage of the connected bus. Therefore, frequency and voltage are taken as the inputs to determine the active and reactive power references, which equate $d$ and q components of the control signals for the current sources. Considering limitation of the battery power, the derived current control signals have upper and lower limits.

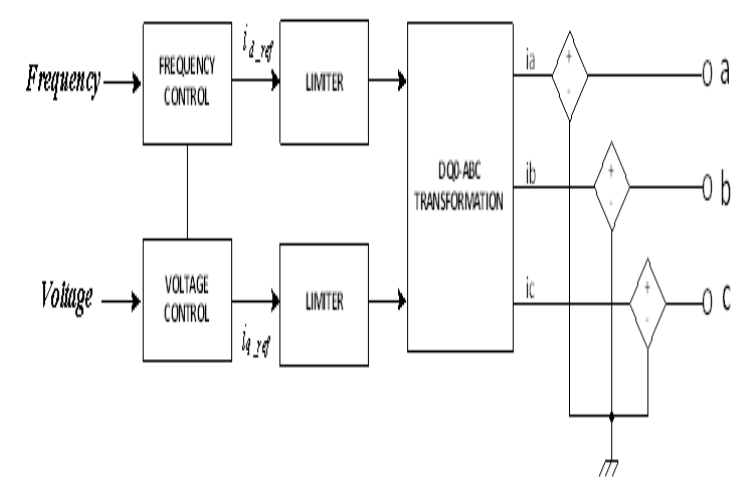

Figure 5. Simplified ESS model

\section{Simulation RESUlts}

In order to assess the performance of the proposed ESS control scheme, three simulation cases were performed. The ESS will form a vital element of a safe, stable island grid. Its main role is to maintain power quality and continuity of supply in critical situations, such as a sudden increase in demand, wind speed variation, and coordination with conventional generators during islanding operation, while preventing the possibility of a power black-out.

\section{Case I}

The main results obtained with a sudden load change are presented in the next figures. The load was varied from 6 MW to $8 \mathrm{MW}$, while the simulation is running, in order to simulate an increase in load demand as shown in Fig. 6 (a). The ESS ensures that the frequency and voltage remain within threshold limits of the power system during a sudden increase in load demand as evident from the Fig. 6(b) and 6(c). Also, it is observed that the ESS increased its output power from $0.045 \mathrm{MW}$ to $0.105 \mathrm{MW}$ since there was a 2 MW shortfall in electrical power as evident from the Fig. 
6(d). The ESS supplied just over 0.06 MW for some time. This allowed sufficient time for the two conventional generators to ramp up. The difference was covered by the two conventional units, as shown in the Fig. 6(e) and 6(f)

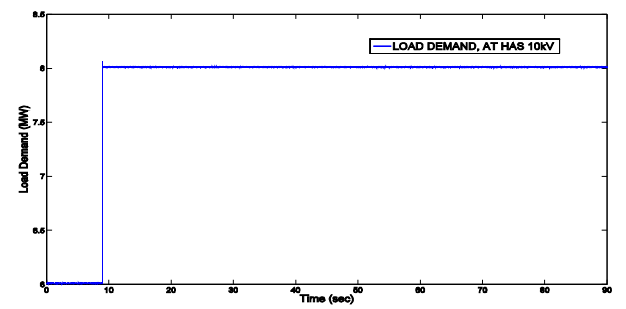

(a)

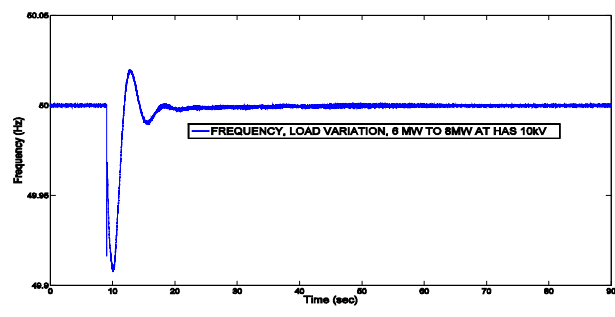

(b)

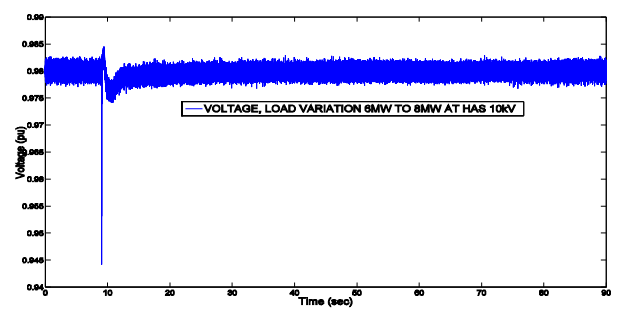

(c)

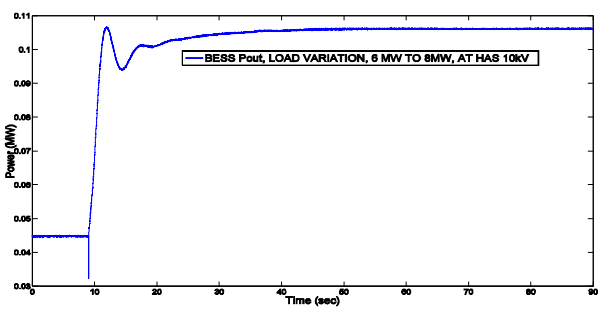

(d)

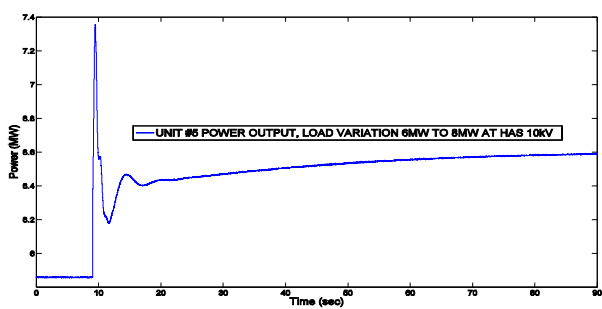

(e)

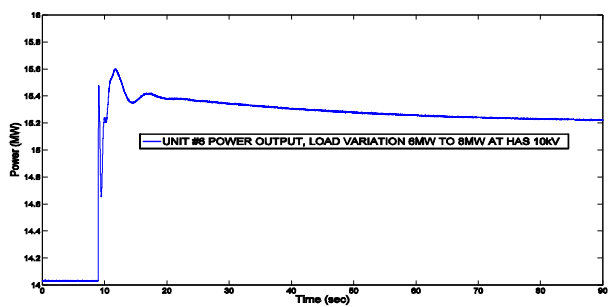

(t)

Fig. 6. Response of load variation (a) load demand (b) frequency, (c) voltage, (d) BESS $P_{\text {out }}$, (e) Unit \#5 $P_{\text {out }}$, and (f) Unit \#6 P out

\section{Case II}

The results obtained with wind speed variation are presented in the next figures. In this particular case, the wind speed was fed in from the forecasting system as shown in Fig. 7 (a). The ESS ensures that the frequency and voltage remain within threshold limits of the power system during wind speed variation as evident from the Fig. 7(b) and 7(c). Also, it is observed that the ESS reduced its output power from $0.045 \mathrm{MW}$ to $0.035 \mathrm{MW}$ since more wind is available as evident from the wind turbine output in the Fig. 7(d). Consequently, the power requirements from conventional generators are also greatly reduced as shown in the Fig. 7(e) and 7(f).

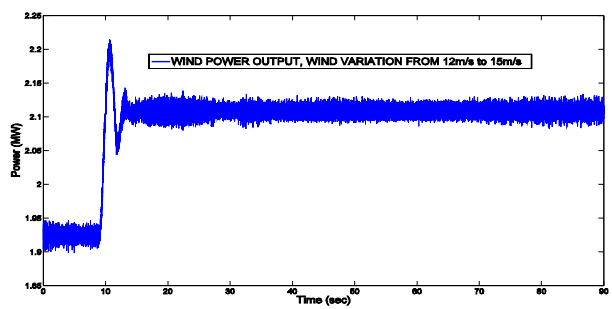

(a)

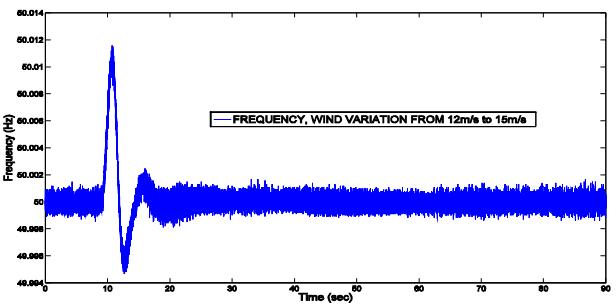

(b)

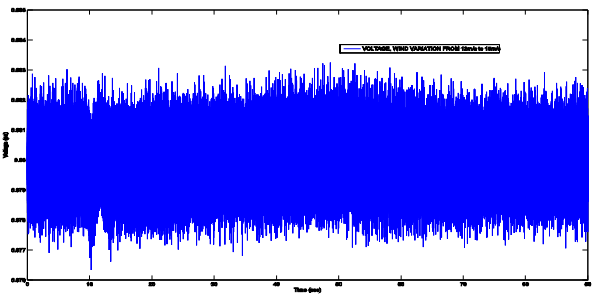

(c) 


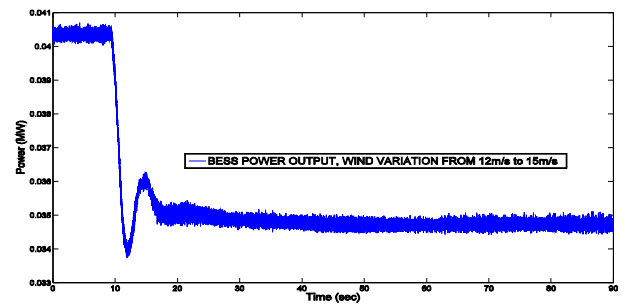

(d)

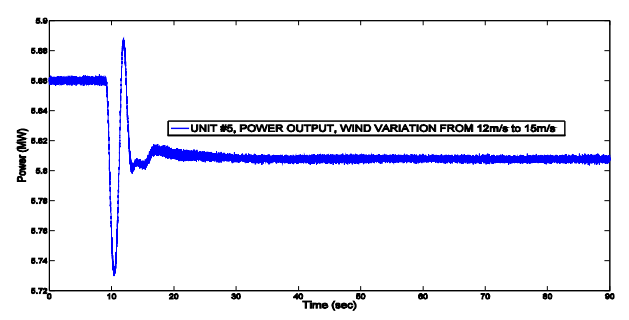

(e)

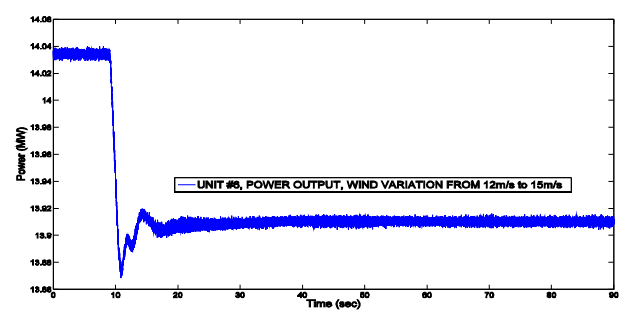

(f)

Fig. 7. Response of wind speed variation (a) wind $P_{\text {out }}$, (b) frequency, (c) voltage, (d) BESS $P_{\text {out }}$, (e) Unit \#5 $P_{\text {out }}$, and (f) Unit \#6 $P_{\text {out }}$

\section{Case III}

In this case, the frequency and voltage response is also conducted with and without the ESS regulation, where two conventional units participated in the secondary regulation control but with no coordinated control activated. In Fig. 8(a) and (b), the frequency and voltage response with BESS regulation control is shown with legend BESS ON + NO COORDINATION (blue curves). Also, the frequency and voltage response without BESS regulation control is shown with legend BESS OFF + NO COORDINATION (green curves), respectively. As it can be seen from Fig. 8 (a, blue curves) that the frequency dropped to $49.88 \mathrm{~Hz}$ and then recovered to the nominal value after $55 \mathrm{sec}$ and settled again at $50 \mathrm{~Hz}$. Due to the absent of coordination control between ESS and the conventional units, the frequency is slowly recovered. Nonetheless, the ESS also helped to maintain power quality by providing instant response to smooth out. The power injections from two conventional units are represented in the Fig. 8(c) and 8(d).

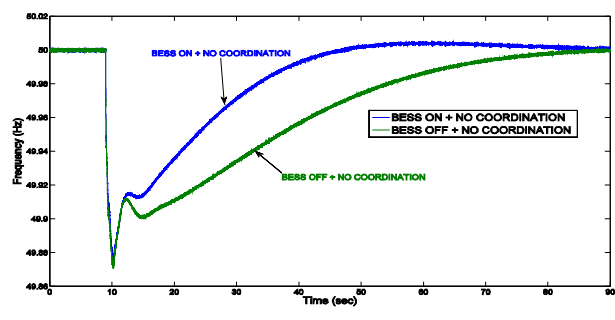

(a)

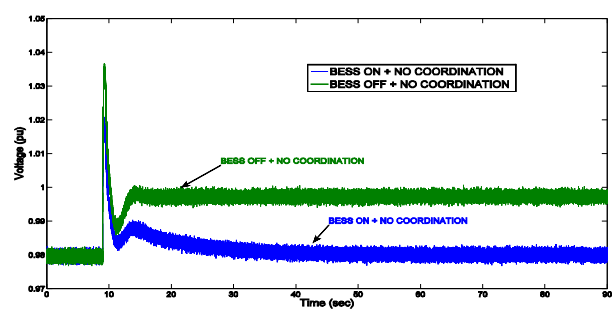

(b)

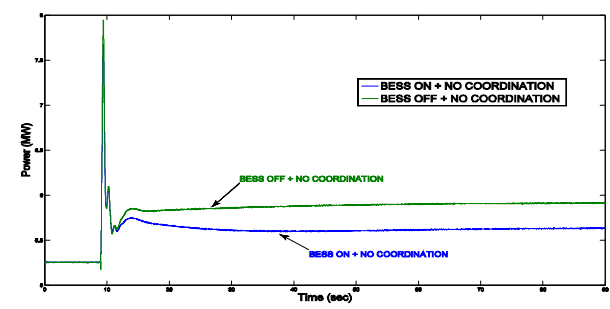

(c)

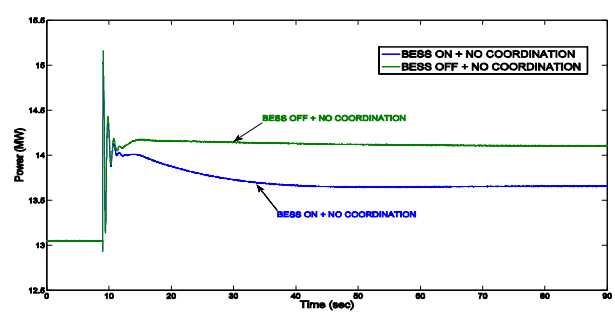

(d)

Fig. 8. BESS regulation with and without no coordinated control (a) frequency, (b) voltage, (c) Unit \#5 $P_{\text {out }}$, (d) Unit \#6 $P_{\text {out }}$

\section{CONCLUSIONS}

Energy is a key issue for sustainable development. Renewable energy is emerging trend as the energy supply solution ensuring reliable and stable supply in such remote communities like island power systems. Electric utilities, transmission and distribution system operators are challenged with the task of matching power supply with ever-changing demand. To make the matter worse, the grid extension is a very costly, difficult and challenging task. In addition, the power production of these variable generation units is hard to control and match with the electricity demand side, effecting the stability and quality of the power system networks. 
Some potential strategies to improve power quality can be a range of measures such as demand side management, increased flexibility of conventional power plants, and appropriate storage solutions. The simulation results demonstrated the possible need of planning energy storage systems for small remote islands, and showed that how energy storage systems fare in real-world applications coupled with better forecasting tools. This would potentially relieve distribution capacity at needed times.

\section{ACKNOWLEDGEMENT}

The work was supported by the Transmission System Operator (TSO), Energinet.dk, the Distribution System Operator (DSO), Østkraft, Bornholm and Technical University of Denmark (DTU). Any opinions, findings, conclusions or recommendations expressed in this material are those of the authors and do not necessarily reflect those of Energinet.DK nor Østkraft. The authors gratefully acknowledge the support received from Dr. Shi You, CET, DTU.

\section{REFERENCES}

[1] Agreement between the Government and Venstre, Danish People's Party, Red-Green Alliance and Conservative People's Party about the Danish energy policy 2012-2020, March 2012, http://www.kemin.dk/Documents/Presse/2012/Energiaftale/Aftale\%2 022-03-2012\%20FINAL.doc.pdf.

[2] T. Ackermann, Wind Power in Power Systems, $1^{\text {st }}$ Edition, Wiley 2005.

[3] Jayakrishnan R. Pillai, Birgitte B. jensen, "Integration of vehicle-togrid in the Western Danish power system," IEEE Transactions on Sustainable Energy, vol. 2 no. 1, 2011, pp. 12-19.

[4] Jacob Østergaard, Qiuwei Wu, Rodrigo G. Valle, "Intelligent control laboratory of PowerLabDK for smart grid technology development," IEEE Workshop on Complexity in Engineering, 2012

[5] Interface specification, draft version, Doc. No. 04EKS0033A004-A, Oct 2011

[6] Seung Tae Cha, "RTDS implementation of Bornholm power system distribution system modeling and analysis," Dept. Electrical Eng., Technical University of Denmark, Lyngby, Internal Report, pp. 1-58, Nov. 2010.

[7] Seung Tae, Cha, Haoran Z., Qiuwei Wu, Arshad Saleem, Jacob Østergaard "Coordinated control scheme of battery energy storage system and distributed generations for electric distribution grid operation," in Proc. $38^{\text {th }}$ Annual Conference of the IEEE Industrial Electronics Society, 2012 